Mr Aleksandar Cakić, major, dipl. inž

Vojna akademija - Odsek logistike, Beograd

\section{PROBLEM POKAZATELJA BEZBEDNOSTI RADA SA SREDSTVIMA INTEGRALNOG TRANSPORTA U VOJSCI}

UDC: $355.415 .2: 355.69$

Rezime:

Bezbednosti manipulacije sredstvima integralnog transporta ne posvećuje se dovoljno pažnje u Vojsci. Postoji određena paralela sa bezbednošću putnog saobraćaja, ali je ona nedovoljno prilagođena karakteristikama sredstava integralnog transporta i načinima organizacije i realizacije transportnih lanaca. Analizom je utvrdeno kako se normativnim dokumentima reguliše praćenje bezbednosti sredstava integralnog transporta. Anketirane su i prikazane potrebe upravnih organa pojedinih snabdevačkih službi sa pokazateljima bezbednosti pri manipulisanju sredstvima integralnog transporta. Zaključuje se da je potrebno formirati odgovarajuće sisteme pokazatelja bezbednosti sredstava integralnog transporta koji bi bili prilagođeni hijerarhijskim nivoima i snabdevačkim lancima.

Ključne reči: sredstva integralnog transporta, pokazatelj, bezbednost sredstava integralnog transporta.

\title{
INDICATORS OF INTEGRAL TRANSPORT MEANS SAFETY IN THE ARMY
}

Summary:

Not enough attention is paid to integral transport means safety in the army. There is a parallel with road traffic safety but not enough adapted to characteristics of integral transport means and the methods of transportation chains organization and realizations. The examination has shown how normative documents regulate monitoring of integral transport means safety. It confirms and shows the needs of supply service managing bodies for indicators of integral transport means safety during operation. Therefore, there is a need to form adequate systems of integral transport means safety which will be adapted to hierarchical levels and supply chains.

Key words: integral transport means, indicator, integral transport means safety.

\section{Uvod}

Bezbednosti $\mathrm{u}$ oblasti transporta $\mathrm{u}$ Vojsci posvećuje se dosta pažnje, zbog čega se ova oblast posebno prati. Međutim, problem je što ne postoji razrađena metodologija praćenja bezbednosti manipulacije sredstvima integralnog transporta i događaja vezanih za ova sredstva.

Takođe, ne postoji podela odgovornosti između rukovaoca pretovarne mehanizacije i odgovornog starešine, tako da se često dešava da se izveštava samo o događajima koje nije moguće sanirati na nivou osnovne jedinice.

\section{Pokazatelji bezbednosti za sredstva integralnog transporta definisani normativnim aktima}

U Vojsci se posebno izveštava o vanrednim događajima u koje spadaju i nezgode pri manipulaciji teretima $u$ paletnim lancima. Nezgode su najčešći 
vanredni događaji, pa se njihova analiza obavlja onako kako to definišu operativni organi. U Uputstvu o izveštavanju, evidentiranju i analizi vanrednih događaja $u$ Vojsci SCG tačno su definisani pregledi po kojima se analiza sprovodi, odnosno pokazatelji koji se koriste. U okviru te oblasti definisani su pojmovi koji imaju značajan uticaj i na analizu, a to su: vanredni događaj i vanredni događaj u odgovornosti vojne organizacije.

Kao vanredni događaji ne vode se $\mathrm{i}$ ne evidentiraju nezgode, bez obzira na propust vozača, sa novčanom štetom do 10000 bodova prema Pravilniku o nadležnostima starešina u Vojsci pri odlučivanju o šteti i postupku za naknadu štete. Ovakvi događaji evidentiraju se samo na nivou stručnih službi.

U evidentiranju i analizi vanrednih događaja ne prate se i ne vode pokazatelji već samo neki podaci i činjenice o samom događaju, vrsti događaja i posledicama.

$\mathrm{Za}$ analizu nezgoda koje predstavljaju vanredni događaji koriste se isključivo apsolutni pokazatelji, $i$ to:

- ukupan broj nezgoda definisanih kao vanredni događaji;

- broj nezgoda u odgovornosti vojne organizacije;

- učesnici u nezgodi u odgovornosti vojne organizacije;

- časovna, dnevna i mesečna neravnomernost nastanka nezgode $\mathrm{u}$ odgovornosti vojne organizacije;

- posledice nezgoda definisanih kao vanredni događaji.

U putnom saobraćaju pod nezgodom se podrazumeva nezgoda na putu u kojoj je učestvovalo najmanje jedno vozilo $u$ pokretu, i u kojoj je jedno ili više lica poginulo ili povređeno ili je izazvana mate- rijalna šteta. Analogno tome, pod nezgodom se može smatrati događaj na putu ili na manipulativnim površinama u kojem je učestvovalo najmanje jedno sredstvo integralnog transporta u pokretu, i u kojoj je jedno ili više lica poginulo ili povređeno, ili je izazvana materijalna šteta.

Pokazatelji bezbednosti za sredstva integralnog transporta unekoliko su podudarni sa pokazateljima bezbednosti putnog saobraćaja. Bezbednost drumskog saobraćaja u društvu, kod nas i u drugim zemljama, izražava se različitim pokazateljima. Svi oni mogu se razvrstati u tri osnovne grupe. Prema važećem pravilu o bezbednosti vojnog putnog saobraćaja [2] mogu se izdvojiti sledeće grupe pokazatelja:

1. Apsolutni pokazatelji bezbednosti drumskog saobraćaja su podaci dobijeni neposrednim opažanjem, merenjem i evidentiranjem. Apsolutni pokazatelji bezbednosti, analogni onima iz drumskog saobraćaja, mogu biti:

- ukupan broj nezgoda,

- broj nezgoda u kojima je bilo poginulih,

- broj nezgoda u kojima je bilo nastradalih,

- broj poginulih lica u nezgodama,

- broj povređenih (teže ili lakše) lica u nezgodama,

- broj manipulatora - vozača,

- broj sredstava,

- broj izvršenih operacija, itd;

2. Relativni pokazatelji su oni koji predstavljaju odnos između nekog apsolutnog pokazatelja (posmatrane vrednosti) i nekog broja ili ukupne veličine skupa koja se posmatra. Relativni pokazatelji bezbednosti razmatraju se po grupama, a to su: 
- pokazatelji učestalosti nezgoda, koji predstavljaju odnose između nekog apsolutnog pokazatelja i pređenog puta ili časova rada, $\mathrm{tj}$. ostvarenog transportnog rada (broj nezgoda/ukupni rad sredstava, broj poginulih ili povređenih lica/1000 mč, itd.);

- pokazatelji gustine nezgoda, koji predstavljaju odnos između apsolutnih pokazatelja i broja sredstava (broj nezgoda/100 sredstava, broj poginulih ili povređenih lica/100 sredstava, itd.);

- pokazatelji izloženosti nezgodama koji predstavljaju odnose apsolutnih pokazatelja i broja manipulanata koji učestvuju u radu (broj nezgoda/100 radnika, broj poginulih ili povređenih lica/100 radnika, itd.);

3. Dinamički pokazatelji bezbednosti su oni koji predstavljaju odnose između dva ili više relativnih pokazatelja.

\section{Pokazatelji bezbednosti za sredstva integralnog transporta koji se prate u Vojsci Srbije i Crne Gore}

U stručno-specijalističkoj analizi bezbednosti saobraćaja, koja je detaljnija i šira u odnosu na deo analize vanrednih događaja koji se odnosi na nezgode, svrstavaju se i nezgode koje su nastale na utovarno-istovarnim radovima. Ovu analizu vrše organi SbSl na svim nivoima komandovanja. Metodologija analize definisana je Pravilom o bezbednosti putnog saobraćaja u Vojsci SCG i instrukcijama SbU.

U okviru stručne analize bezbednosti saobraćaja koriste se apsolutni i relativni pokazatelji bezbednosti saobraćaja.
Apsolutni pokazatelji, precizirani definicijom bezbednosti saobraćaja, koji se koriste u stručno-specijalističkoj analizi bezbednosti saobraćaja su: broj nezgoda, broj poginulih lica, broj teže i lakše povređenih lica, visina materijalne štete.

Poslednjih godina visina materijalne štete se evidentira, ali se ne analizira sa aspekta realne procene štete i pariteta cena u toku posmatranog perioda. Takođe, ne diferenciraju se lakše i teže povređena lica u nezgodama, već se evidentira i analizira samo njihov ukupan broj, što nema posebnog opravdanja.

Svi pregledi apsolutnih pokazatelja koji se koriste u godišnjim analizama bezbednosti saobraćaja su, shodno uticaju analize vanrednih događaja, razvrstani na dve grupe: saobraćajne nezgode vojnih vozila i saobraćajne nezgode vojnih vozila u odgovornosti vojne organizacije.

Pored navedenih apsolutnih pokazatelja $u$ analizama bezbednosti saobraćaja koriste se i sledeći pokazatelji:

- broj sredstava na upotrebi,

- broj manipulatora,

- časovna, dnevna i mesečna neravnomernost nastajanja nezgoda.

Relativni pokazatelji bezbednosti saobraćaja, koji su precizirani definicijom bezbednosti saobraćaja i koji se koriste u stručno-specijalističkoj analizi bezbednosti saobraćaja su: učestalost i težina nezgoda.

Poseban problem je što se ne prate oštećenja koja su nastala na teretima, odnosno samim paletama. Oštećenja na robi javljaju se kasnije preko knjigovodstvene evidencije i to retko na mestu nastanka oštećenja već najčešće na krajevima lanaca kod samog korisnika. 


\section{Anketa pokazatelja bezbednosti pri manipulisanju sredstvima integralnog transporta}

Anketa je imala za cilj da se utvrde potrebe upravnih organa snabdevačkih službi za određenim pokazateljima, $t \mathrm{j}$. da li se neki podaci prate a ne koriste se ili, obrnuto, da li se neki pokazatelji ne prate, a trebalo bi da se prate. Formulisana anketa namenjena je za upravne strukture snabdevačkih službi po hijerarhijskim nivoima na kojima se javljaju i koriste paletni lanci, a to su hijerarhijski nivoi Generalštaba (odnosno Uprave u sektoru logistike) i korpusi.

Ispitivanje je obavljeno po nivoima Tehničke, Intendanske i Saobraćajne službe, što je prikazano u tabeli.

$\mathrm{U}$ ispitivanju nisu uzimane $\mathrm{u}$ obzir Sanitetska, Veterinarska i Građevinska služba po hijerarhijskim nivoima, jer su one donekle ili potpuno odvojene od ostalih snabdevačkih službi. Takođe, postoji i velika različitost obima poslova i organizacije u okviru ovih službi u odnosu na ostale snabdevačke službe. Sanitetska i Veterinarska služba u miru nisu previše opterećene snabdevanjem materijalnim sredstvima, što je samo razlog više za potvrdu ispravnosti ovakve odluke.

\begin{tabular}{|l|c|c|c|c|}
\hline \multicolumn{1}{|c|}{ Mesta prikupljanja podataka } \\
\hline & $\begin{array}{c}\text { Uprava Sek- } \\
\text { tora logistike } \\
\text { GS }\end{array}$ & $\begin{array}{c}\text { Pozadinska } \\
\text { baza GŠ }\end{array}$ & $\begin{array}{c}\text { Beogradski } \\
\text { korpus }\end{array}$ & $\begin{array}{c}\text { Pozadinske } \\
\text { baze korpusa } \\
\text { (Bg, NS, Kg) }\end{array}$ \\
\hline $\begin{array}{l}\text { Načelnik } \\
\text { Tehničke } \\
\text { službe }\end{array}$ & $\sqrt{ }$ & $\sqrt{ }$ & $\sqrt{ }$ & $\sqrt{ }$ \\
\hline $\begin{array}{l}\text { Načelnik In- } \\
\text { tendantske } \\
\text { službe }\end{array}$ & $\sqrt{ }$ & $\sqrt{ }$ & $\sqrt{ }$ & $\sqrt{ }$ \\
\hline $\begin{array}{l}\text { Načelnik Sa- } \\
\text { obraćajne } \\
\text { službe }\end{array}$ & $\sqrt{ }$ & $\sqrt{ }$ & $\sqrt{ }$ & $\sqrt{ }$ \\
\hline
\end{tabular}

Ispitivanjem nisu obuhvaćene ni Mornaričkotehnička i Vazduhoplovnotehnička služba, koje se veoma razlikuju po karakteristikama tereta i obimu poslova koji su specifični za njihove vidove. Naime, teret se nalazi u njihovoj nadležnosti kao i organizacija paletnih lanaca. Ove dve službe veoma su specifične sa aspekta tereta i mesta manipulisanja koja su usko vezana za teritorijalnu nadležnost ovih službi, i zbog toga nisu ispitivane.

Obim tereta u paletnim lancima, u miru, u okviru ranije nabrojanih službi je višestruko manji nego kod ispitivanih službi.

Za ispitivanje je uzet sistem po hijerarhijskim nivoima snabdevanja, sa činiocima na mestima koja su kompetentna za odlučivanje. Ovi ispitanici su eksperti, jer poseduju adekvatna stručna znanja i, nalaze se na odgovarajućim mestima $u$ hijerarhiji. Pored stručnih znanja poseduju i iskustvo u radu na rešavanju zadataka i prevazilaženju problema koji se javljaju u sistemima snabdevanja Vojske SCG. Svi ispitanici svakodnevno rade na zadacima u sistemu snabdevanja, na organizaciji i realizaciji snabdevačkih lanaca i usmeravanju robnih tokova.

Ispitivanje je u potpunosti obuhvatilo samo nivo Generalštaba, dok je kod korpusnog nivoa obuhvaćen samo Beogradski korpus u celini i baze susedna dva korpusa.

U anketi su ispitanici mogli da za svako pitanje zaokruže neki od ponuđenih odgovora ili da dopišu svoj odgovor. Odgovori koji su prikazani u grafikonima nisu komplementarni. Ispitanici su mogli da za svaki ponuđeni pokazatelj zaokruže po rubrikama - prati se, odnosno treba pratiti.

Dobijeni su različiti rezultati između potreba za pokazateljima i postojećim pra- 
ćenjem pokazatelja. Iskazane su potrebe ispitanika za većim brojem pokazatelja.

Prilikom anketiranja problem je predstavljala činjenica da je anketa bila unificirana za različite profile stručnjaka, tako da pojedini ispitanici nisu želeli da odgovore na neka pitanja, jer se nisu javljala u njihovom radu.

Pokazatelji bezbednosti sredstava integralnog transporta, koji su predloženi u anketi, dati su na osnovu Uputstva o izveštavanju, evidentiranju $i$ analizi vanrednih događaja u VJ, kao i paralela sa pokazateljima bezbednosti putnog saobraćaja, uz napomenu da dinamički pokazatelji nemaju upotrebnu vrednost za sredstva integralnog transporta (IT). Svi su grupisani u pokazatelje vanrednih događaja, apsolutne i relativne pokazatelje.

Većina ispitanika prati pokazatelje onako kako je definisano Uputstvom o izveštavanju, evidentiranju i analizi vanrednih događaja u VJ, i smatra da su oni i korisni i neophodni za praćenje (slika 1).

Kod apsolutnih pokazatelja bezbednosti većina ispitanika ih prati i smatra da je praćenje potrebno (slika 2).

Relativni pokazatelji bezbednosti sredstava IT uglavnom se ne prate, ali većina ispitanika smatra da ih je potrebno pratiti (slika 3). Kod dinamičkih pokazatelja bezbednosti sredstava IT izraženo je da se oni ne prate, a nema ni iskazane potrebe ispitanika da se prate.

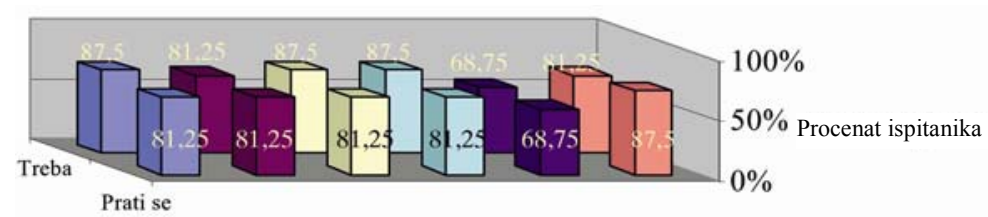

QVD u odgovornosti vojne organizacije

- Ukupan broj nezgoda definisan kao vanredni dogadaj

$\square$ Broj nezgoda u odgovornosti vojne organizacije

口Uéesnici u nezgodi u odgovornosti vojne organizacije

- Casovna, dnevna i mesečna neravnomernost nastanka nezgode u odgovornosti vojne organizacije

$\square$ Posledice nezgoda definisanih kao VD

Sl. 1 - Pokazatelji bezbednosti za sredstva IT kao vanredni dogadaj

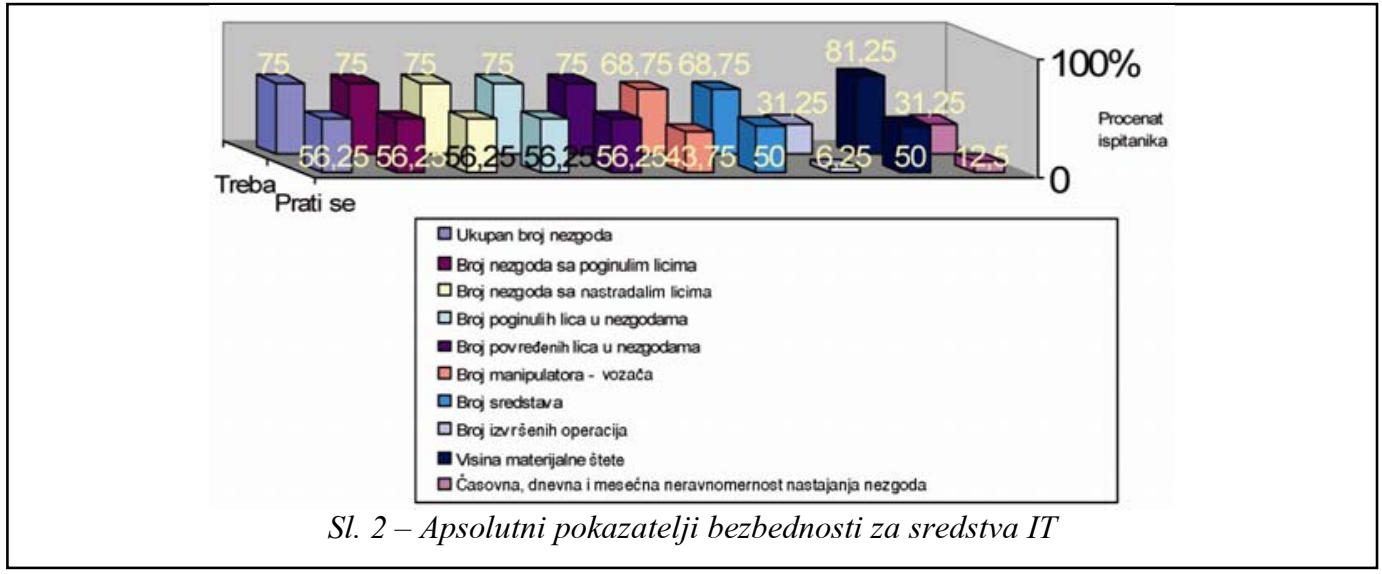



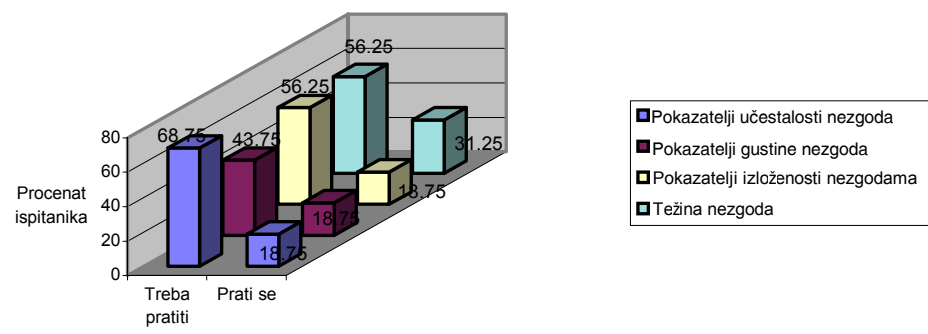

Sl. 3 - Relativni pokazatelji bezbednosti za sredstva IT
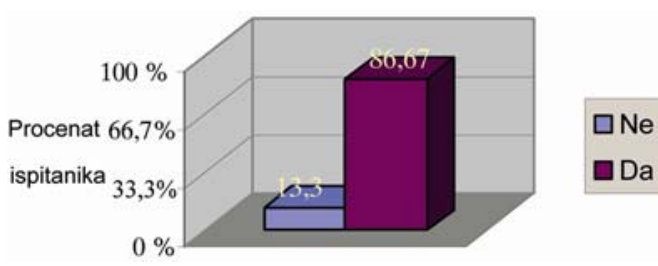

Sl. 4 - Uticaj pokazatelja bezbednosti IT pri donošenju odluka

Ispitanici su istakli da im pokazatelji bezbednosti pomažu pri donošenju odluka, što je naročito značajno, jer veliki broj ovih pokazatelja prate ispitanici (slika 4).

Na pitanje da li nekad viši hijerarhijski nivo zahteva podatke iz ove grupe, a da oni nisu adekvatno prikupljeni, većina ispitanika je odgovorila da se takve situacije ne dešavaju. Samo 6,25\% ispitanika napomenulo je da viši hijerarhijski nivo zahteva podatke o količini oštećene robe nastale zbog nezgoda.

Od ukupnog broja samo $31,25 \%$ ispitanika odgovorilo je da se na njihovom hijerarhijskom nivou javljaju paletni lanci sa određenim količinama tereta kao ulaznim tokovima, a samo $18,75 \%$ je odgovorilo da su zastupljeni izlazni tokovi paletnih lanaca. Ovaj podatak je potvrda činjenice da se paletni lanci završavaju na ulaznom nivou Generalštaba ili najkasnije na korpusnom nivou.

\section{Zaključak}

Može se uočiti da postojeći načini praćenja bezbednosti sredstava integralnog transporta nisu zadovoljavajući. Potrebno je definisati novi sistem pokazatelja bezbednosti za sredstva integralnog transporta, koji se bitno razlikuje od pokazatelja bezbednosti putnog saobraćaja. Pored toga, više pažnje treba posvetiti i minimalnim oštećenjima koja se javljaju u toku manipulacije sredstvima integralnog transporta.

Evidencija koja treba da se uspostavi mora da omogući praćenje podataka po sredstvima, radnim operacijama, procesima u lancima i po hijerarhijskim nivoima. Pri tome ona treba da omogućava kvalitetnu sliku o bezbednosti manipulacije sredstvima integralnog transporta, ali i bezbednost u realizaciji celokupnog lanca snabdevanja.

Literatura:

[1] Cakić, A.: Istraživanje i izbor pokazatelja stanja i korišćenja sredstava integralnog transporta, magistarski rad, Beograd, 2000.

[2] Pravilo o bezbednosti vojnog putnog saobraćaja u Vojsci Jugoslavije, SbU GŠ VJ, Beograd, 1997.

[3] Uputstvo o izveštavanju, evidentiranju i analizi vanrednih događaja u Vojsci Jugoslavije, Generalštab VJ, Beograd, 1997. 